\title{
AS LUTAS E A AGENDA SINDICAL PARA A VALORIZAÇÃO DO MAGISTÉRIO NA PERSPECTIVA DA CNTE: QUAL A CONTRIBUIÇÃO DO NOVO PLANO NACIONAL DE EDUCAÇÃO?
}

Heleno Manoel Gomes de Araújo Filho*

RESUMO: A Confederação Nacional dos Trabalhadores em Educação (CNTE), composta por 49 entidades filiadas, representando trabalhadores e trabalhadoras em educação das redes públicas dos Estados, do Distrito Federal e vários municípios brasileiros - mobilizou com outras entidades ligadas ao campo educacional - uma luta intensa pela aprovação do novo Plano Nacional de Educação (PNE), alcançando êxito no dia 25 de junho de 2014, com a promulgação da Lei Federal n. 13.005/14. As 20 metas e suas 254 estratégias definem os eixos para a elaboração das políticas educacionais nos próximos 10 anos. É tarefa dos governos das três esferas federativas e dos movimentos sociais tratar e cuidar da universalização da educação básica com qualidade e equidade, da ampliação do acesso de jovens ao ensino superior, da gestão democrática do ensino, da valorização dos profissionais da educaçáo e do financiamento da educação pública. Neste artigo apresento o processo de atuação da CNTE pela aprovação deste novo plano, dando ênfase às conquistas voltadas para a valorização profissional dos trabalhadores e das trabalhadoras em educação, estabelecidas nas metas 15, 16, 17 e 18. Cabe observar que, ainda que o PNE esteja aprovado como lei, será necessário o acompanhamento vigilante das entidades que lutaram por sua aprovaçáo e o consideram uma conquista

\footnotetext{
* Coordenador do Fórum Nacional de Educação. Secretário de Assuntos Educacionais da CNTE. Brasília. DF., Brasil. E-mail de contato: heleno@cnte.org.br
} 
em relação à situação atual para que seja garantido na prática o direito pleno à educação com a qualidade social merecida e a valorização dos seus profissionais.

Palavras-chave: CNTE. Valorização profissional. Sistema nacional de educação. PNE.

\section{The struggles and the union agenda for the valorization of teaching under the CNTE perspective: what is the contribution of the new National Education Plan?}

ABSTRACT: The Confederação Nacional dos Trabalhadores em Educação (CNTE) [National Confederation of Workers in Education], composed by 49 affiliated entities, representing educational workers from state public schools, the Federal District and several Brazilian municipalities mobilized, along with other entities linked to the educational field, an intense fight for the approval of the new Plano Nacional de Educação (PNE) [National Education Plan], which then occurred on June 25th, 2014, with the promulgation of the Federal Law n. 13.005/14. The 20 goals and the 254 strategies of the new plan define the axis for the elaboration of educational policies during the next ten years. It is the three-sphere federal government and the social movements' task to handle and attend to the universalization of basic education with quality and equality, the increase of young people's access to higher education, the financing of the public system, the valorization/development of education professionals, and the democratic administration of education. In this article I will present how the CNTE acted towards the approval of this new plan, emphasizing the achievements related to the professional appreciation of workers in education, established in the following goals 15, 1617 and 18. It should be noted that, even though the PNE was enacted as law, vigilant monitoring (by the entities which have fought for its approval and consider it an achievement in relation to the current situation) will be necessary if full right to education with the deserved social quality as well as the valorization of its professionals is to be assured.

Keywords: NCWE. Teacher appreciation. National education system. NEP. CNTE. PNE. 


\section{APRESENTAÇÃO}

A

Constituição Brasileira de 1988, após a aprovação da Emenda Constitucional $n^{\circ} .53$ de 2006, estabelece que a valorização dos profissionais da educação escolar básica pública deve ser garantida, através da formulação de planos de carreira, com ingresso exclusivamente por concurso público de provas e títulos, aos das redes públicas e aplicação do Piso Salarial Profissional Nacional (PSPN). Indicando no parágrafo único do artigo 206, que lei específica disporá sobre as categorias de trabalhadores considerados profissionais da educação básica e sobre a fixação de prazo para a elaboração ou adequação de seus planos de carreira, no âmbito da União, dos Estados, do Distrito Federal e dos Municípios.

A lei $\mathrm{n}^{\circ} 12.014$, de 06 de agosto de 2009, alterou o artigo $61 \mathrm{da}$ Lei de Diretrizes e Bases da Educação Nacional (LDB), com a finalidade de cumprir o dispositivo da Constituição Federal (CF), discriminando as categorias de trabalhadores que se devem considerar profissionais da educação, que são os que estão em efetivo exercício e foram formados em cursos reconhecidos:

I - professores habilitados em nível médio ou superior para a docência na educação infantil e nos ensinos fundamental e médio;

II - trabalhadores em educação portadores de diploma de pedagogia, com habilitação em administraçáo, planejamento, supervisão, inspeção e orientação educacional, bem como com títulos de mestrado ou doutorado nas mesmas áreas;

III - trabalhadores em educação, portadores de diploma de curso técnico ou superior em área pedagógica ou afim.

Consideramos que houve avanços nos princípios da valorização dos profissionais da educação básica com a aprovação da Emenda 
Constitucional $n^{\circ} .53 / 2006$, no entanto, ainda estamos com as conquistas só no papel.

A Lei do Piso Salarial Profissional Nacional, aprovada em 2008, beneficia apenas os profissionais do Magistério, deixando de fora os demais trabalhadores da educação e, mesmo assim, até hoje não foi aplicada por todos os Estados e Municípios brasileiros.

Os planos de cargos e carreira, exigência do texto original da CF/1988, reafirmado pela LDB/1996, Fundef/1996, EC nº. 19/1998, PNE/2001, EC n. 53/2006, Fundeb/2007, PSPN/2008 até o presente momento não foi elaborado por muitos Estados e Municípios, e em outros que criaram, enfrentamos dificuldades na sua implementação.

As condiçóes precárias na infraestrutura das escolas, a falta de equipamentos e material didático, o número excessivo de alunos por turma, a deficiência na formação inicial e continuada dos trabalhadores, a ausência da gestão democrática são fatores reais que prejudicam a valorização dos profissionais da educação.

\section{A CONAE 2014 E A VALORIZAÇÃO DOS PROFISSIONAIS DA EDUCAÇÃO}

O tema central da Conferência Nacional de Educação (CONAE 2014): "O PNE na Articulação do Sistema Nacional de Educação: Participação Popular, Cooperação Federativa e Regime de Colaboração", indica o instrumento necessário para articular o Sistema Nacional de Educação (SNE), que é o Plano Nacional de Educação (PNE), Lei n. 13.005, publicada no Diário Oficial da União em 25 de junho de 2014. Porém, para que tenhamos um SNE que seja colocado em prática no país, tem que ser garantida a efetiva participação popular na elaboração, acompanhamento e avaliação, bem como, seja firmado um pacto federativo e republicano entre os entes federados.

Os trabalhadores e as trabalhadoras, representados pela Confederação Nacional dos trabalhadores em Educação (CNTE), entendem que para alcançar o direito à educação e a valorização dos profissionais o Sistema Nacional de Educação deve, necessariamente, conferir qualidade 
social ao aprendizado, empregar caráter sistêmico às políticas educacionais e universalizar as matrículas da educação pública regular. $\mathrm{O}$ combate às desigualdades regionais, princípio básico do SNE, deve ser perseguido através da continuidade das políticas sistêmicas voltadas à interação dos níveis básico e superior; do protagonismo do trabalho e das relaçóes sociais no currículo; da expansão do financiamento; da consolidação da gestâo democrática; da implementação de uma cultura positiva para avaliação dos sistemas, das redes, das escolas/instituiçóes, dos estudantes e dos profissionais; da efetiva valorizaçáo da carreira dos profissionais da educação (com diretrizes nacionais que assegurem formação, salário, carga horária e condições de trabalho); da reestruturação das escolas (infraestrutura, tecnologias, espaços, tempos e métodos pedagógicos); da regulamentação da oferta subsidiária do setor privado; do chamamento da sociedade à defesa da educaçáo pública, dentre outros previstos nos eixos da Conae.

Consideramos que o perfil dos profissionais da educação deve ser pautado pela concepção de educação como processo construtivo e permanente, o que implica na formação de um profissional crítico, que valorize a construção coletiva do conhecimento, utilize o diálogo como prática do ensino e respeite a cultura e subjetividade de cada estudante; que participe e estimule a organização dos trabalhadores em educação, dos estudantes, dos pais e máes, fortalecendo a comunidade escolar; contribua com o desenvolvimento da gestão democrática da escola, como forma de valorizar a efetiva participaçáo da comunidade escolar, nas deliberaçóes administrativas, financeiras e pedagógicas da escola. É importante a participação na construção do projeto político pedagógico na escola, garantindo a autonomia necessária para trabalhar o currículo e o tempo escolar, com base na realidade local; desenvolva a capacidade de articular teoria e prática (ação/reflexão/ação) que se leve em conta à realidade da sala de aula e da profissão; que promova a integraçáo e interdisciplinaridade curriculares, dando significado e relevância aos conteúdos básicos, articulados com a realidade social e cultural, voltados tanto às exigências da educação básica e superior, quanto à formação do cidadão e da cidadã. É necessário que valorize sua vivência investigativa e o aperfeiçoamento da prática educativa, mediante a participação em projetos de pesquisa e extensão desenvolvidos nas Instituiçôes de Ensino Superior (IES) e em grupos de estudos na educação básica; participe 
dos processos de formação continuada, em consonância com as atuais demandas educacionais e sociais e com as mudanças epistemológicas no campo do conhecimento; desenvolva as competências e habilidades para o uso das tecnologias de informação e comunicação (TIC), na perspectiva de transformação da prática pedagógica. Além de desenvolver a reflexão crítica sobre as diferentes linguagens midiáticas, incorporando-as ao processo pedagógico, com a intenção de possibilitar o desenvolvimento da criticidade e criatividade; que defenda a concepçáo de educação inclusiva com vistas ao exercício da docência no respeito às diferenças e no reconhecimento e valorização à diversidade, tendo como compromisso o desenvolvimento e a aprendizagem dos alunos, por meio de um currículo que favoreça a escolarização e estimule as transformaçóes pedagógicas das escolas, visando à atualização de suas práticas, como meio de atender às necessidades dos estudantes durante o percurso educacional.

Para alcançar este perfil defendemos uma base sólida na formação inicial e continuada, aplicaçáo integral do Piso Salarial Profissional Nacional, a jornada compatível com a demanda da comunidade escolar, o desenvolvimento na carreira que estimule o profissional a estudar e trabalhar de forma coletiva e a garantia das condiçóes adequadas de trabalho. Entendemos que esses indicadores devem ser tratados indissociavelmente com vistas a melhorar as condiçóes de vida e trabalho dos/as educadores/as e a qualidade da educação.

Exigimos (e o documento final da Conae 2014 trata destes indicadores) a constituição de uma política nacional de formação de educadores, que atenda às demandas de professores e funcionários de escola e à devida aplicação do Piso Salarial Nacional para os profissionais da educação, estabelecido pelo inciso VIII, do artigo 206, da Constituição Federal.

No indicador condiçóes de trabalho para valorização dos profissionais da educaçáo, o $\$ 3^{\circ}$ do artigo 212 da Constituição Federal de 1988, além de determinar que a distribuição dos recursos públicos assegurará prioridade ao atendimento das necessidades do ensino obrigatório, no que se refere a universalização, determina que deve ser garantido o padrão de qualidade e equidade, nos termos do Plano Nacional de Educação. 
No tocante à remuneração é preciso que o Governo Federal cumpra com o dever de enviar ao Congresso Nacional um projeto de lei que atenda a determinação constitucional, haja vista a Lei Federal no. 11.738/08, que trata do Piso Salarial Profissional Nacional ser limitada aos Profissionais do Magistério da Educação Básica Pública. Exigimos uma nova Lei do Piso Salarial Profissional Nacional para os Profissionais da Educação.

A organização e mobilização dos segmentos da comunidade escolar e dos setores da sociedade civil, como aconteceram na Conferência Nacional da Educação Básica - Coneb/2008, Conae/2010, Conae/2014 e pela aprovaçáo do PNE (Lei n. 13.005/14), devem continuar para garantir a adaptação ou elaboração e implementação dos planos de educação nos Estados, Distrito Federal e Municípios, pois, estes são os caminhos que farão as mudanças necessárias para colocar a educação como prioridade nacional, garantindo o acesso e a permanência de todos na escola, o direito dos estudantes de aprender e a valorização dos profissionais da educação.

\section{QUAIS AS CONTRIBUIÇÕES DO PNE PARA GARANTIR A VALORIZAÇÃO PROFISSIONAL?}

A Confederação Nacional dos Trabalhadores em Educação, considera que houve avanços no novo PNE com relação as políticas voltadas ao conjunto dos Profissionais da Educação Básica Pública, tais como:

- O pleno reconhecimento dos funcionários em todas as políticas de valorização profissional - formação, remuneração e carreira, inclusive na inserção deste segmento da categoria dos trabalhadores em educação em censo específico, a ser realizado pelo Inep/MEC, com a finalidade de melhor conhecer os funcionários e de propor políticas públicas que atendam às demandas desses trabalhadores escolares (Estratégia 18.5).

- No tocante à formação profissional, o PNE conclama o Estado brasileiro a ofertar gratuitamente, dentro dos limites da LDB, a formaçáo em nível superior a todos os integrantes do magistério, bem como a 
profissionalização dos funcionários em cursos de nível médio, superior e com acesso à formação continuada e à pós-graduação, tal qual previstas para os/as professores/as.

- Questão de grande relevância é a previsão de consolidação da política nacional de formação de professores e dos funcionários, a qual se pretende unificada, respeitando-se as peculiaridades de cada processo formativo. (Estratégia 18.4)

- Quanto à questão salarial, assumiu-se o compromisso de, em seis anos, equiparar a remuneração média dos/as professores/as com a de outros profissionais com mesmo nível de escolaridade - tendo o piso nacional como a principal referência dessa política (Meta 17), e, no caso dos funcionários, propôs-se regulamentar em dois anos o piso salarial do art. 206, VIII da CF, o qual servirá de referência para os planos de carreira da categoria. (Meta 18)

- A luta contra a terceirização e a improvisação nas redes de ensino ganhou força com a limitação indicada no PNE para contratos temporários de professores/as (10\% no total) e funcionários (50\%). (Estratégia 18.1).

\section{AS LUTAS E A AGENDA SINDICAL DA CNTE E DAS SUAS ENTIDADES FILIADAS}

$\mathrm{Na}$ agenda de lutas da CNTE e suas entidades filiadas estão, também, as mobilizaçóes pelos cumprimentos dos prazos estabelecidos na Lei do PNE, intensificamos as nossas açóes para que até dia 24 de junho de 2015, todos os Estados, o Distrito Federal e todos os Municípios tenham as Leis Estaduais, Distrital e Municipais dos Planos de Educação. Planejar os próximos 10 anos é de fundamental importância para garantir as políticas de valorização profissional. Neste sentido, indicamos as seguintes açóes para alcançar as metas 15, 16, 17 e 18 da Lei n. 13.005/14 (PNE):

\section{Metas 15 e 16:}

1. Elaborar diagnóstico das necessidades de formação dos profissionais da educaçáo, preferencialmente em nível dos fóruns de educação e de formação profis- 
sional instalados nos estados e municípios (estratégia 15.1 e 16.1);

2. Assegurar cursos de formação inicial e de pós-graduação com bolsas de estudo para os profissionais que atuam nas escolas públicas (estratégias 15.2, 15.3, 15.9, 15.10, 15.12 e 16.5);

3. Pressionar pela ampliação da Plataforma Freire, do MEC, especialmente para as áreas de formação continuada de professores e funcionários (estratégia 15.4 e 16.4);

4. Participar dos processos de elaboração/adequação de conteúdos para a formação inicial e continuada dos profissionais escolares, valorizando as práticas de ensino e os estágios acadêmicos (estratégias 15.5 a 15.8 e 15.13);

5. Implantar, no prazo de 1 ano de vigência da Lei, política nacional de formaçáo continuada para os(as) profissionais da educação (estratégia 15.11 e 16.2);

Metas 17 e 18:

1. Pressionar o MEC a instituir o fórum permanente para acompanhamento da atualização progressiva do piso salarial do magistério. $\mathrm{O}$ mesmo deve ser proposto às secretarias de educação, nos estados e municípios, para fins de acompanhamento local das metas 17 e 18 do PNE (Estratégias 17.1 e 18.8);

2. Atuar junto aos órgãos de governo e de Estado (Ministério Público) para aprovar planos de carreira para todos os profissionais da educaçáo, observados os critérios de valorização previstos no PNE (Estratégias 17.3, 18.4 e Meta 18);

3. Participar da elaboração de cronogramas para substituição dos contratos temporários por profissionais concursados, à luz dos percentuais estabelecidos na estratégia 18.1;

4. Atuar na definição de novos critérios para o estágio probatório da categoria (Estratégia 18.2); 
5. Acompanhar os critérios de formulação e aplicação da prova nacional, a ser aplicada pelo MEC, para formação de cadastro de profissionais do magistério que ficará à disposição das redes de ensino de todo o país para admissão de pessoal em caráter permanente (Estratégia 18.3);

6. Acompanhar e incentivar a aplicação do censo dos funcionários da educação em todas as escolas do país (Estratégia 18.5).

\section{CONSIDERAÇÕES FINAIS}

Para enfrentar o desafio da valorização dos profissionais da educação é preciso atuar em vários campos de batalha: na negociação direta com os municípios, estados e a união; na realização das etapas municipais, estaduais e nacional das conferências de educação; na implementação do novo Plano Nacional de Educação e dos Planos Estaduais, Distrital e Municipais de Educação; na instalação e fortalecimento dos Fóruns Estaduais e Municipais de Educação, na organização e fortalecimento dos conselhos (de classe, escolar, de educação, de acompanhamento do Fundeb, da alimentação escolar); nos encaminhamentos dos fóruns permanentes da Política Nacional de Formaçáo dos Docentes; na implementação pelos Institutos Federais de Educação da Política de Formação Continuada, através do Profuncionários.

O custo aluno-qualidade deve ser a referência para alcançar a qualidade social da educação e a valorização dos seus profissionais, inverter a lógica do financiamento da educação é o fator preponderante para atingir as metas, objetivos e estratégias dos Planos de Educação.

Promover uma reforma tributária e política é preparar o terreno para aplicar os planos de educaçáo no país. Pensar o Brasil como nação vai exigir uma melhor distribuição das riquezas produzidas, de modo a atender todas as regióes, na perspectiva de reduzir às desigualdades existentes. As medidas de fortalecimento do controle social e mudanças no processo eleitoral para escolha dos membros dos poderes executivos e legislativos devem acompanhar a aplicação de mais recursos para educação 
pública. Esses são os desafios que necessitam ser enfrentados pela Nação brasileira para promover o avanço acelerado na educação escolar básica, com qualidade social e valorização dos profissionais que nela atuam.

As bases para uma nova realidade educacional no país estão lançadas. Contudo, sua concretude depende mais do que nunca do compromisso dos gestores públicos e da mobilização social. (CNTE, 2014)

\section{SUGESTÕES DE TEXTOS PARA LEITURA}

A CNTE possui inúmeros subsídios a respeito desses e de outros temas relacionados à qualidade da educação pública e à valorização de seus profissionais. Todos estão disponíveis para consulta e reprodução nos seguintes endereços:

- Sobre o Piso Salarial: <http://www.cnte.org.br/analise-lei11738 ou www.cnte.org.br >;

- Sobre Planos de Carreira: < http://www.cnte.org.br/diretrizes-carreira>;

- Sobre Formação Profissional: < http://www.esforce.org.br/revista-formacao >;

- Sobre Financiamento da Educação: <http://www.esforce.org.br/ revista-financiamento>;

- Sobre Profissionalização dos Funcionários de Escola: < $\underline{\text { http:// }}$ www.esforce.org. br/revista-funcionarios $>$.

\section{REFERÊNCIAS}

BRASIL. Constituição (1988). Constituição da República Federativa do Brasil. 18. ed. atual. ampl. São Paulo: Saraiva, 1998.

. Constituição (1988). Emenda Constitucional no. 59, de 11 de novembro de 2009. Acrescenta $₫ 3^{\circ}$ ao art. 76 do Ato das Disposiçôes Constitucionais Transitórias para reduzir, anualmente, a partir do exercício de 2009, o percentual da Desvinculação das Receitas da União incidente sobre os recursos destinados à 
manutenção e desenvolvimento do ensino de que trata o art. 212 da Constituiçáo Federal, dá nova redação aos incisos I e VII do art. 208, de forma a prever a obrigatoriedade do ensino de quatro a dezessete anos e ampliar a abrangência dos programas suplementares para todas as etapas da educação básica, e dá nova redaçáo ao $\$ 4^{\circ}$ do art. 211 e ao $\$ 3^{\circ}$ do art. 212 e ao caput do art. 214 , com a inserção neste dispositivo de inciso VI. Diário Oficial da Uniáo, Brasília, DF., 12 nov. 2009.

BRASIL. Lei no. 9.394, de 20 de dezembro de 1996. Estabelece as diretrizes e bases da educação nacional. Diário Oficial da Uniáo, Brasília, DF., 20 dez. 1996.

. Lei no. 9.424, de 24 de dezembro de 1996. Dispóe sobre o Fundo de Manutenção e Desenvolvimento do Ensino Fundamental e de Valorização do Magistério, na forma prevista no art. $60, \$ 7^{\circ}$, do Ato das Disposiçóes Constitucionais Transitórias, e dá outras providências. Diário Oficial da Uniáo, Brasília, DF., 24 dez. 1996.

. Lei no. 10.172, de 09 de janeiro de 2001. Aprova o Plano Nacional de Educação e dá outras providências. Diário Oficial da União, Brasília, DF., 10 jan. 2001.

. Lei no. 11.738, de 16 de julho de 2008. Regulamenta a alínea "e" do inciso III do caput do art. 60 do Ato das Disposiçóes Constitucionais Transitórias, para instituir o piso salarial profissional nacional para os profissionais do magistério público da educação básica. Diário Oficial da União, Brasília, DF., 17 jul. 2008.

. Lei no. 12.014, de 6 de agosto de 2009. Altera o art. 61 da Lei no. 9.394, de 20 de dezembro de 1996, com a finalidade de discriminar as categorias de trabalhadores que se devem considerar profissionais da educação. Diário Oficial da Uniâo, Brasília, DF., 7 ago. 2009.

. Lei n. 13.005, de 25 de junho de 2014. Aprova o Plano Nacional de Educação para o decênio 2014-2024 e dá outras providências. Diário Oficial da Uniáo, Brasília, DF., 26 de jun 2014.

. Ministério da Educação. CONEB. Documento Final da Conferência Nacional da Educaçâo Básica. Brasília, DF.: MEC, 2008.

- Ministério da Educação. Avaliação do Plano Nacional de Educação: 2001/2008. Brasília, DF.: MEC/Inep, 2010.

CADERNOS DE EDUCAÇĀO. Brasília: CNTE, ano XVIII, n. 28, 2a ed. ampl., 2014. [PNE: Mais Futuro para a Educação Brasileira]. 
CONGRESSO NACIONAL DA CONFEDERAÇÃO NACIONAL DOS TRABALHADORES EM EDUCAÇÃO. XXXIII. Caderno de Deliberaçóes. Brasília, DF.: CNTE. 2011.

FÓRUM NACIONAL DE EDUCAÇÃO. Conae 2014. Conferência Nacional de Educação: documento/referência. Brasília: MEC, 2013.

Recebido em 01 de junho de 2015.

Aprovado em 15 de setembro de 2015.

DOI: http://dx.doi.org/10.1590/CC0101-32622015156052 